\title{
Influence of Bio-Organic Modification of Nutrient Solution on Mineral and Carbon Nutrition of Plants of Tomato in Greenhouses
}

\author{
Adaev N.L. \\ The Department of agricultural technology \\ The Chechen State University \\ Grozny city, Chechen Republic \\ mr.adaev61@mail.ru
}

Bamatov I.M.

Laboratory of physical and chemical methods of research and analysis the Biochemical faculty of The Chechen State University, Grozny city, Chechen Republic ibragim-1991@mail.ru

\author{
Adaev A.N. \\ Department of selection and seed \\ Chechen Research Institute of Agriculture» \\ Grozny city, Chechen Republic \\ ahmed944an@mail.ru \\ Amaeva A.G. \\ Department of agricultural technology \\ The Chechen State University \\ Grozny city, Chechen Republic \\ asaet-6666@mail.ru
}

\author{
Zanilov A.H. \\ Department of transfer of innovative technologies in agricultural complex \\ Federal Center of Agricultural Consulting Services and \\ Retraining Staff of Agricultural Complex \\ Sergiyev Posad city, the Moscow Region \\ agro-center@inbox.ru
}

\begin{abstract}
Experience has proven that, in search of innovative solutions it is often necessary to return to the known fundamental principles of the functioning of agroecosystems. The only problem remains the question of giving the "outdated" solutions a certain manufacturability and their adaptation to the current production process.

Considering that the effectiveness of carbon nutrition of plants is important for the biochemical processes, one of such innovative solutions offered for consideration is the inclusion of a complex of organic and microbiological substances in the nutrient solution of hydroponic systems on the mineral rock with the development of appropriate programs for the automation of feed modes.
\end{abstract}

Keywords - salt content, drainage, assimilation of minerals, modification of feed system, carbohydrates.

\section{INTRODUCTION}

Modern greenhouse vegetable farming is one of the most innovative and knowledge-intensive sectors of the agroindustrial complex of Russia. Production vegetable-growing complexes are created with the aim of highly profitable production by saving fuel and energy resources, increasing yields, reducing production costs, and effective use of investments [1].
In modern vegetable-growing plants the maximum number of factors is regulated: light mode, temperature mode, moisture supply mode, gas composition, quality of irrigation water, mineral nutrition. Among the noted factors, the greatest difficulty is the regulation of the diversity of characteristics in the nutritional segment, which, moreover, must be corrected when the indicators of the other modes change.

A scientific approach to the development of any industry implies the continuous improvement of the elements of the production chain. Despite the high adaptability of the territorial-industrial complex, in order to find new solutions, it is necessary to return to the fundamental classical foundations on the understanding that it is necessary to give them characteristics adapted to modern requirements of production.

\section{METHODS AND MATERIALS}

The production experience was conducted in the conditions of LLC Greenhouse Complex "Jug-Agroholding" (Chechen Republic, Grozny city) in 2017-2018. The plant is divided into 4 blocks. The complex was built by Hortilife BV and Ammerlaan and Construction BV (Netherlands). The production area is 8.9 ha.

The tests were carried out on the early indeterminate hybrid Merlis F1 with a density of 2.4 plants $/ \mathrm{m} 2$. Mineral 
wool by Izovol Agro company (Belgorod) was used as an artificial rock. Date of planting is 2017-2018 years.

As a bio-organic component, organic fertilizer Activator Carbon (5 1/ha) and microbiological fertilizer Extrasol (5 l/ha) were fed into the drip irrigation system. Blocks No. 3 and No. 4 were allotted for the experimental plot with a total area of 4.9 ha. The comparison was carried out with the indicators of the block number 1 and number 2 (4.0 hectares) with the reference technology. Amino-acid preparations Maxifol Ruthfarm (5 1/ha) and Radifarm (5 1/ha) were used as stimulants in them. The flow of funds in all blocks was carried out three times: January 16, 2018; January 25, 2018 and February 01, 2018.

Estimation of efficiency of mineral nutrition was carried out by a comparative difference of agrochemical drainage indicators between 1.2 and 3.4 compared blocks. As parameters, EC, pH, N-NO3, P2O5, K2O, Ca, Mg, Mn, Zn, Fe were used.

The effectiveness of carbon nutrition was estimated by a complex of indirect parameters, including the degree of assimilation of mineral substances and the comparison of the data obtained with literature sources.

\section{RESULtS}

Analysis of drainage samples obtained from the compared blocks was made 21 days after the first submission of the tested means - February 6, 2018.

TABLE I. DRAIN ANALYSIS DATA, MG / L.

\begin{tabular}{|c|c|c|c|c|c|}
\hline \multirow{2}{*}{$\begin{array}{c}\text { Drainage } \\
\text { parameters }\end{array}$} & \multicolumn{2}{|c|}{ Control blocks } & \multicolumn{2}{|c|}{ Test blocks } & \multirow{2}{*}{$\begin{array}{c}\text { Difference, } \\
\%\end{array}$} \\
\hline & 1 & 2 & 3 & 4 & \\
\hline \multirow[t]{2}{*}{$\mathrm{N}-\mathrm{NO} 3$} & 167 & 179 & 159 & 159 & \\
\hline & \multicolumn{2}{|c|}{173} & \multicolumn{2}{|c|}{159} & +8.1 \\
\hline \multirow[t]{2}{*}{$\mathrm{P} 2 \mathrm{O} 5$} & 356 & 324 & 260 & 184 & \\
\hline & \multicolumn{2}{|c|}{340} & \multicolumn{2}{|c|}{222} & +34.7 \\
\hline \multirow[t]{2}{*}{$\mathrm{K} 2 \mathrm{O}$} & 165 & 186 & 108 & 141 & \\
\hline & \multicolumn{2}{|c|}{176} & \multicolumn{2}{|c|}{125} & +29 \\
\hline \multirow[t]{2}{*}{$\mathrm{Ca}$} & 1.5 & 0.75 & 0.26 & 0.5 & \\
\hline & \multicolumn{2}{|c|}{113} & \multicolumn{2}{|c|}{38} & +66.4 \\
\hline \multirow[t]{2}{*}{$\mathrm{Mg}$} & - & 1.78 & 1.51 & 1.69 & \\
\hline & \multicolumn{2}{|c|}{178} & \multicolumn{2}{|c|}{164} & +5.1 \\
\hline \multirow[t]{2}{*}{$\mathrm{Mn}$} & 0.17 & 0.14 & 0.08 & 0.05 & \\
\hline & \multicolumn{2}{|c|}{0.16} & \multicolumn{2}{|c|}{0.07} & +56 \\
\hline \multirow[t]{2}{*}{$\mathrm{Zn}$} & 0.09 & 0.13 & 0.16 & 0.17 & \\
\hline & \multicolumn{2}{|c|}{0.11} & \multicolumn{2}{|c|}{0.17} & -35 \\
\hline \multirow[t]{2}{*}{$\mathrm{Fe}$} & 0.32 & 0.38 & 0.18 & 0.29 & \\
\hline & \multicolumn{2}{|c|}{0.35} & \multicolumn{2}{|c|}{0.24} & +31 \\
\hline \multirow[t]{2}{*}{$\mathrm{pH}$} & 6.3 & 5.92 & 5.73 & 6.08 & \\
\hline & \multicolumn{2}{|c|}{6.11} & \multicolumn{2}{|c|}{5.91} & 0.2 \\
\hline
\end{tabular}

The data in Table 1 demonstrate the relative regularity of the behavior of the concentration of mineral substances depending on the types of additives in the nutrient solution in the compared variants.

In experimental blocks $(3,4)$ with the use of organic and microbiological fertilizers, an increase in the assimilation of the main macronutrients is noted. The use of nitrate nitrogen is higher by $8.1 \%$, phosphorus - by $34.7 \%$, potassium - by $29 \%$, calcium - by $66.4 \%$, magnesium - by $5.1 \%$. The effect on the assimilation of microelements also shows an increase in the availability of manganese - by $56 \%$ and iron - by $31 \%$. In the control blocks $(1,2)$ with the use of amino-acid preparations, an increased absorption of zinc was noted - by $35 \%$. From the point of view of the need to compensate for the missing elements, it is easier to carry out the adjustment of the nutrient solution in one of the indicators, especially if it is a minornutrient element. In our case, it is zinc, the additional amount of which can be compensated also as leaf-feeding dressing.

Considering that the observation period occurred in the phase of active ripening of the fruits, the noted tendencies correspond to the conditions for the absorption of basic mineral substances by tomato plants. During this period, the pace of vegetative growth slows down, and the flow of minerals is subject to adjustment. So, with the inadmissibility of reducing nitrogen and potassium, it is recommended to increase the phosphorus content, the need for which increases during the fruiting period. [3]. The table shows that with a general increase in the use of nitrogen, phosphorus and potassium by plants from a solution, the maximum difference falls on phosphorus is $34.7 \%$. This fact indicates that the bioorganic component is able to optimize the mineral nutrition of plants in accordance with the needs of tomato plants in a certain period of development.

Increasing the absorption of quality elements - phosphorus, potassium, etc., allows you to avoid excessive intake of nitrogen into tomato plants, which often manifests itself in excessive development of the vegetative mass and delayed the formation and ripening of fruits.

A similar trend indicating the effect of the bio-organic component on increasing the efficiency of mineral nutrition was manifested in 2014 under the conditions of LLC "AgroCom" (Baksansky district, Kabardino-Balkan Republic). The average increase in availability from the nutrient solution was $15.5 \%$ for nitrate nitrogen, $19.4 \%$ for calcium, $1.4 \%$ for magnesium, and $6.7 \%$ for phosphorus. The total concentration of salts in the drainage of the experimental variant was lower by $14.9 \%[4]$.

Considering the relationship between the presence of carbohydrate substances in solution and the transformation of nitrogen compounds, it is important to familiarize yourself with the conclusions of the classic and founder of the agrochemical science D.N. Pryanishnikov. In his work "Ammonia is the alpha and omega of protein transformation in plants", Dmitry Nikolaevich offers the presence of carbohydrates in the root zone as one of the most important conditions for nitrogen absorption. The transformation of ammonia, which came both directly and by reduction from nitrate forms, is not involved in the process of the formation of proteins outside the presence of carbohydrates. Not being able to communicate with aspartic and glutamic acids, ammonia in free form acts as a toxic substance for plants, as a result of which the nitrate forms cease to be converted and accumulate in plants and fruits in their original form. [5].

As a result of the analysis of the marc and fruit of the tomato of the greenhouse complex "Yug-Agroholding", it was found that the content of nitrate nitrogen in the fruits of the 
experimental blocks was 2 times lower than in the control areas at a relatively equal concentration in the marc. The concentration of ammonia in the marc from the substrate of blocks 3,4 (experience) was lower than in blocks $(1,2)$ in 100 times. This fact indicates that the plant in the experimental plots consumed ammonia from the nutrient solution without experiencing its negative effect.

The basis of the autotrophic nature of a plant organism, that is, the ability to build its body from inorganic substances, has two functions - mineral nutrition and photosynthesis, associated with the regulation of air nutrition [6]. In this regard, the study of the regularity of carbon nutrition of plants is an important task in greenhouse vegetable gardening.

In modern greenhouses, the use of fertilizing with carbon dioxide is considered as an indispensable element of intensive technology of cultivation of vegetables, including tomato.

On average, $94 \%$ of the dry basis of plants is synthesized from water and carbon dioxide. The remaining 6\% comes from minerals. The lack of $\mathrm{CO}_{2}$ often serves as a factor limiting the assimilation of carbohydrates and, accordingly, the growth and development of plants.

By increasing carbon dioxide in the greenhouse air, it is possible to reduce the accumulation of nitrates in vegetables [7].

The aim of the experiment was to approximate the production conditions of tomato plants on an artificial substrate to natural conditions. Under natural conditions, plants develop better and demonstrate maximum productivity with an optimal ratio of mineral, organic and microbiological components in the root zone. Accordingly, the inclusion of sterile liquid organic fertilizer and a microbiological component in a nutrient solution consisting of dissolved mineral fertilizers entails an increase in carbon dioxide concentration in the root zone. In classical agriculture, the intensity of $\mathrm{CO}_{2}$ emissions (soil respiration) positively correlates with land fertility [8].

In contrast to the soil, the artificial substrate in its original state does not contain organic compounds. They are formed with the development of the root system both due to their secretions, and due to root fibrillas, which die off during the whole period of growing vegetables. A significant source of carbon dioxide in the medium created in this way is microorganisms introduced into the root zone, developing due to the additional organic matter included in the feed system.

A visual assessment of the state of the root system made it possible to state an increase in its mass in the experimental blocks. According to various data, the contribution of roots to the release of carbon dioxide corresponds to the volume of carbon dioxide produced by microorganisms [9].
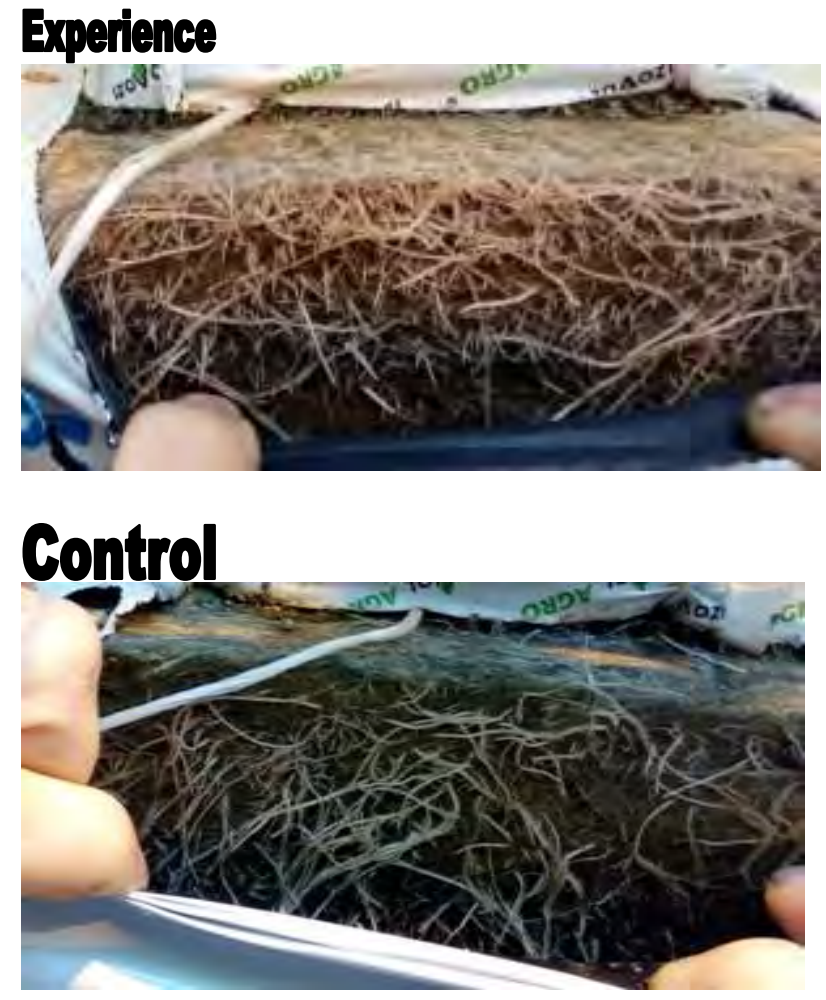

Fig 1. Comparison of the state of the root system in the experimental and control blocks.

The darker color of the mineral substrate without the test substances being fed into the solution (the image on the right) indicates a more intense rate of root system death, which requires additional energy expenditure by the plants for the formation of new roots. Moreover, decomposition, and in fact, rotting of the roots with the formation of toxic substances for newly formed young roots, can lead to poisoning of the whole plant organism and, consequently, to a decrease in their productivity, as well as an increase in the phytopathogenic background [4].

Depending on the processes occurring in the substrate, both harmful and neutral substances and useful substances can be formed, among which vitamins, enzymes, amino-acids and other compounds that stimulate root growth can be distinguished. As a result, there is an increase in the absorbing surface of the roots and at the same time the volume of organic substances released by the roots increases. 


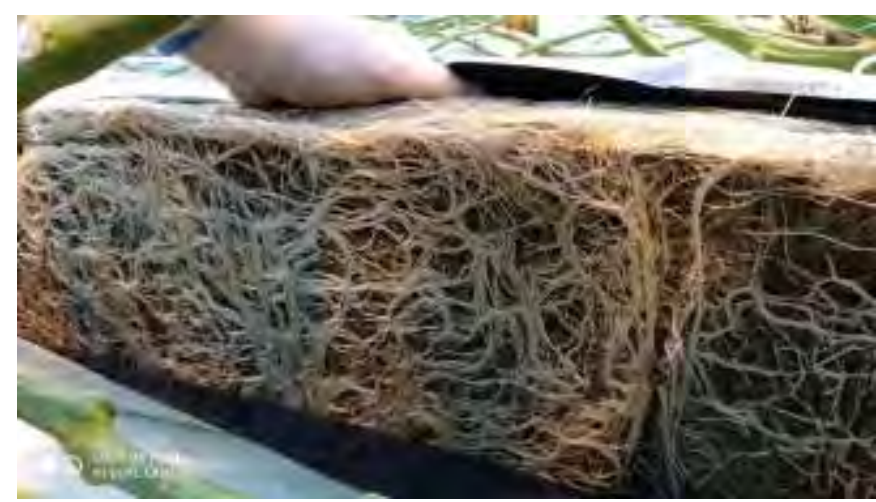

Fig 2. The state of the root system of plants in the experimental block of the greenhouse complex "Yug-Agroholding".

From this experience, it can be concluded that carbon is fed to plants not only through the leaf apparatus, but also directly through the root system. Despite the fact that traditionally the intensity of photosynthesis is associated with the concentration of carbon dioxide in the air, it can be assumed that the assimilation of $\mathrm{CO}_{2}$ through the root system plays an equally important role in providing the plant body with such "building material" as carbon.

At this stage, a new and advanced technology of carbon dioxide supply is considered by saturating the nutrient solution of hydroponic systems with it to a concentration of $0.3-1.1 \mathrm{~g} / \mathrm{l}$. This allows us to better organize the supply of $\mathrm{CO}_{2}$, since the concentration of $\mathrm{CO}_{2}$ in the air is difficult to control, which is clearly seen on the graph (Fig. 3). As a result of the regulation of climatic parameters, it is often necessary to open greenhouse transom, which entails a decrease in the concentration of carbon dioxide with effective photosynthetic active radiation indicators.

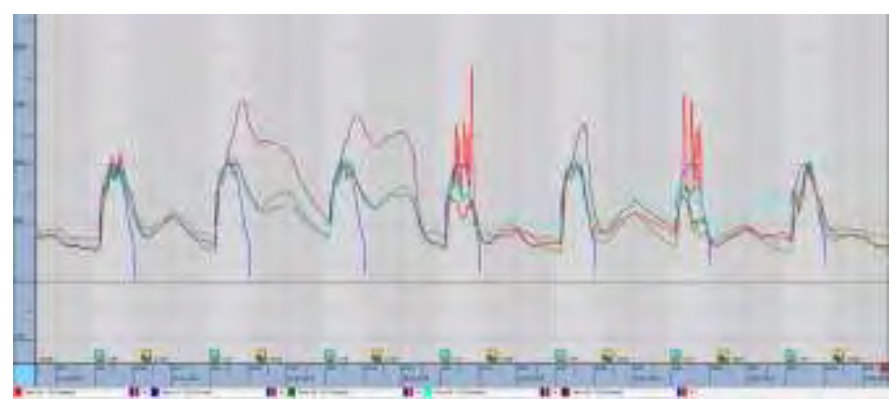

Fig. 3. Fluctuations of $\mathrm{CO}_{2}$ concentrations in the air of the greenhouse complex "Yug-Agroholding".

The authors' team (Kovalenko D.V., Smirnov A.P.) registered a patent under the number RU $2527065 \mathrm{C} 2$ "Method of feeding plants grown on protected ground [10]. The method involves feeding plants to accelerate the formation of plant tissues grown in greenhouses by watering with water saturated with carbon dioxide to a concentration of $50 \mathrm{ml}$ of gaseous $\mathrm{CO}_{2}$ per 1 liter of water at a water temperature of $12-20^{\circ} \mathrm{C}$. In this case, watering plants carried out three times a day. The method allows to reduce the time of cultivation, increase yields and use environmentally safe feeding. The text of the patent contains more than 40 sources of literature in which ways of supplying carbon dioxide to the root system of plants are described in one way or another. However, the method has not become widespread.

Investigating the effect of the bio-organic component of the nutrient solution, in this work, it is estimated as a direct contribution to the increase in the effectiveness of mineral nutrition, as well as mediated. At the same time, the initial role of the carbohydrate complex is assigned as accelerators of biochemical processes in plants, including those that stimulate growth and development. The conditions created subsequently for the formation of carbon dioxide and its absorption are a positive additional effect from the means used.

An additional effect of the increase in $\mathrm{CO} 2$ is associated with a decrease in the $\mathrm{pH}$ of the nutrient solution, which leads to an increase in the solubility of fertilizers and a better absorption of calcium and magnesium by plants. [7]. The results of the agrochemical analysis of drainage, shown in Table 1, are a confirmation of this thesis on the understanding that the increase in the availability of mineral substances to plants under the action of carbon also extends to such elements as nitrogen, phosphorus, potassium, manganese, iron.

\section{CONCLUSION}

As practice shows, in search of innovative solutions it is often necessary to return to the known fundamental principles of the functioning of agroecosystems. The only problem remains the question of giving the "outdated" solutions a certain manufacturability and their adaptation to the current production process.

Considering that the effectiveness of carbon nutrition of plants is important for the biochemical processes, one of such innovative solutions offered for consideration is the inclusion of a complex of organic and microbiological substances in the nutrient solution of hydroponic systems on the mineral substrate with the development of appropriate programs for the automation of feed modes.

\section{References}

[1] P.N. Vinogradov, S.S. Shevchenko, O.L. Sedov, S.G. Tishkovec, A.V. Ipatov, V.V. Grishechko, V.G. Pritula, D.Ju. Mozgovoj, A.V. Izhutkin, "Guidelines for the technological design of greenhouses and greenhouse plants for growing vegetables and seedlings", Moscow: Rosinformagroteh, 2014, p. 103.

[2] Soil buffering, Available at: https://studopedia.ru/2_22157_bufernost-p ochvi.html

[3] L.S. Gil, A.I. Pashkovskij, L.T. Sulima, "Modern vegetable growing of the protected and open ground", Practical guide, Zhytomyr: Ruta, 2012, p. 468.

[4] A.H. Zanilov, A.H. Leshkenov, "The bio-organic component of the nutrient solution of hydroponic systems as an element of increasing the productivity of protected ground”, Gavrish №4, 2017, pp. 33-37.

[5]. V.D. Naumov, "Scientific heritage of Academician D.N. Pryanishnikov", Izvestija TSHA, Release 1, 2016, pp. 116-126

[6] Hothouse study, Digest of "Hothouse World". Tomatoes: technology. M., 2000, № 2, p. 136, Hothouse study. Technologies. Digest of materials of "Tomato Club", M., 2011, p.143

[7] K.B. Bogdanov, E.I. Uskov, "Plant nutrition with carbon dioxide in greenhouses”, Gavrish №5, 2004, pp. 11-17. 
[8] R.R. Bender, W.J. Haegel and E. Bellow, "Modern Soybean Varieties Nutrient Uptake Patterns", Better Crops, 2015, №2, pp. 7-10.

[9] S.A. Blagodatskij, A.A. Larionova, I.V. Evdokimov, "The contribution of the respiration of roots to the $\mathrm{CO}_{2}$ emission from the soil", Soil breathing, NCBI RAN Pushhino, 1993, pp. 26-32.
[10] "Description of invention to patent", Available at: http://www.freepatent.ru/images/img_patents/2/2527/2527065/patent2527065.pdf 